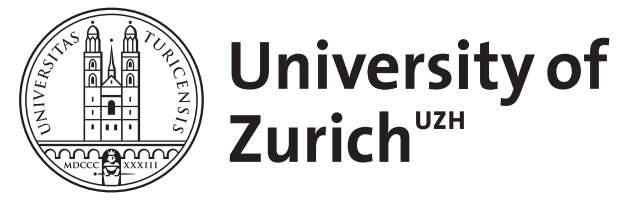

\title{
Algunos apuntes acerca de la cuestión de la 'hibridez' y de la 'dignidad' de las lenguas iberorrománicas
}

\author{
Kabatek, Johannes
}

Posted at the Zurich Open Repository and Archive, University of Zurich ZORA URL: https://doi.org/10.5167/uzh-86160

Book Section

Originally published at:

Kabatek, Johannes (2011). Algunos apuntes acerca de la cuestión de la 'hibridez' y de la 'dignidad' de las lenguas iberorrománicas. In: Congosto Martín, Yolanda; Méndez García de Paredes, Elena. Variación lingüística y contacto de lenguas en el mundo hispánico. In memoriam Manuel Alvar. Madrid: Iberoamericana, 271-289. 


\section{Algunos apuntes acerca de la cuestión de la "hibridez" y de la "dignidad" de las lenguas iberorrománicas}

\section{Johannes Kabatek, Universidad de Tubinga, Alemania}

\section{kabatek@uni-tuebingen.de}

\section{Introducción}

Las siguientes reflexiones derivan de una serie de experiencias de los últimos años, vividas, por un lado, en el seno de diferentes comunidades lingüísticas en situaciones diversas así como, por otro lado, en discusiones con colegas o mediante la lectura de textos tanto científícos como periodísticos. Sirva a modo de ejemplo la siguiente situación de la que fui testigo hace cuatro años. En una conversación entre un funcionario del gobierno regional gallego vinculado a la política lingüística y varias personas implicadas en el proceso de planificación lingüística, alguien decía que en su opinión no tenía mucho sentido apoyar la extensión social de la lengua gallega sin cuidar su propia forma. Insistía en que, en su opinión, si se extendía un gallego híbrido y castellanizado, no se ganaba nada. A esto, el mencionado funcionario respondió que a él no le importaba cómo se hablaba gallego sino que se hablara gallego. A esto, el otro respondió que no estaba de acuerdo porque las lenguas, según él, también tenían su dignidad. Dicho sea de paso que el gallego del funcionario era un gallego fuertemente castellanizado aprendido recientemente mientras que el gallego del otro, aunque también contuviera castellanismos léxicos, tenía fundamento de lengua materna, así que en cierto modo ambos no hacían más que defender su propia forma de hablar.

La contradicción evidente entre las dos posturas es antigua y se puede etiquetar de contraste entre "purismo" y "antipurismo" lingüístico, pero ha adquirido nueva actualidad, desde hace algunos años, en la discusión sobre la hibridez lingüística ${ }^{1}$. Con hibridez lingüística se suele denominar una cierta situación de mezcla de lenguas, junto a hibridización, que sería el proceso que lleva a tal situación ${ }^{2}$. El término, en su adopción por la lingüística, aparece en los estudios de los criollos, a principios de los años setenta (Whinnom 1971), pero si es empleado recientemente en trabajos de lingüística, esto se debe más bien a una adopción desde los estudios literarios y los estudios de la cultura (cultural studies). Desde hace unos años, sobre

\footnotetext{
${ }^{1}$ El término hibridez aparece como traducción española del ingl. hybridity, aunque tiene tradición propia en español, al contrario del menos frecuente islote léxico hibrididad, poco conforme con las reglas de formación de palabras del español y evidente traslado del ingl. hybridity o más bien del alemán Hybridität. También aparece hibridización, sobre el modelo de hybridization.

${ }^{2}$ Para esta distinción, véase Gugenberger 2008, 36.
} 
todo en los estudios "postcoloniales" acerca de las literaturas y culturas latinoamericanas ${ }^{3}$, el término hibridez, tradicionalmente de connotación negativa y opuesto a lo "puro", "auténtico", "homogéneo", de connotación tradicionalmente positiva, es usado adrede, en un acto de apropiación y de concienciación, con connotación opuesta, no solo para describir únicamente una situación de mezcla, sino para darle un nombre identificador y otorgarle connotaciones generalmente positivas: lo híbrido, en vez de considerarse, desde la postura purista, como algo impuro, incorrecto y negativo, se denomina con un nombre científico supuestamente neutro que permita evitar estas connotaciones; es más: se procura, en toda una serie de estudios, de escritos diversos y de discusiones, connotar lo híbrido positivamente, en el sentido de que la mezcla no se considere como defectuosa, sino al contrario, se considera como creativa y fructífera e incluso superior a la "pureza". Esto también vale para la adopción en la lingüística. Lo híbrido se considera superior ya que en la mezcla de lenguas confluyen por lo menos dos, y dos son más que una sola. Al mismo tiempo, la postura que defiende las ventajas de la hibridez coexiste - y necesita coexistir - con una postura contraria a la que se opone y de la cual se nutre, aquella que critica lo mezclado como algo de menor valor, considerando la mezcla como amenaza a la lengua, atacando la "hibridez" o defendiendo lo "puro".

Este debate se presenta, en el mundo hispánico, de múltiples formas y puede referirse, como en la anécdota citada, a cuestiones de contacto entre lenguas en España o a la cuestión del contacto del español y otras lenguas, sobre todo el inglés, en las discusiones acerca del llamado spanglish, por ejemplo.

Ahora bien, lo que llama la atención en este debate metalingüístico que evidentemente preocupa e interesa a los hablantes no es tanto el hecho de que a nivel popular se produzcan contradicciones y discusiones, sino que estas contradicciones parecen hacer eco también a nivel de la discusión científica, con férreas defensas de posturas opuestas. Se procura demostrar, en trabajos de índole científica, la objetividad de un valor determinado de lo mezclado, por un lado, y de lo puro, por otro.

Sin embargo, me parece que una evidente contradicción que se da en el debate metalingüístico cotidiano no debería ser reproducida, sino analizada desde la ciencia, procurando evitar prejuicios y visiones demasiado parciales. En este sentido, si aparece una contradicción entre puristas y antipuristas, antes de buscar argumentos científicos en favor o en contra de una de las dos posiciones, habría que preguntarse por los motivos que llevan a los diferentes protagonistas a defender esta o aquella postura, y, suponiendo que cada una de ellas tendrá su

\footnotetext{
${ }^{3}$ Cf. por ejemplo García Canclini 1990.
} 
lógica interna, su razón propia, llegaremos tal vez a destapar malentendidos o por lo menos a evidenciar las claras incompatibilidades.

En las siguientes líneas procuraremos analizar algunos de los argumentos de la discusión. Partiremos de la separación entre una perspectiva del objeto (lenguaje, lenguas y discursos) y el sujeto hablante, describiendo lo "puro" y lo "híbrido" primero desde la primera, luego desde la segunda perspectiva. En cuanto a la segunda perspectiva, trataremos la cuestión de la valoración subjetiva de las situaciones lingüísticas por parte de los hablantes, con sus efectos sincrónicos que consisten en la visión de las cosas desde un ángulo determinado y sus efectos de predicción futura hecha a partir de la visión sincrónica subjetiva. Entraremos, en este contexto, también en la cuestión de las categorizaciones, con una nota sobre los nombres de las lenguas, y llegaremos, por último, a hablar de protagonistas metalingüísticos, aquellos que con su liderazgo procuran convencer a los hablantes de las ventajas de una postura determinada. Todo lo que sigue se refiere a situaciones del mundo hispánico, pero es aplicable a situaciones de contacto en general. La combinación del análisis de hechos lingüísticos, por un lado, y de hechos ideológicos, por otro, forma parte de una disciplina que podría recibir el nombre de Ideolingüística.

\section{La perspectiva "objetiva"}

Antes de pasar a la perspectiva de los hablantes, me parece oportuno plantear la pregunta de si los objetos sometidos a la discusión tienen alguna existencia real o si se trata de meras construcciones. Curiosamente, en el debate sobre "hibridez" y "purismo" es frecuente encontrar la negación del objeto al que uno se opone: se dice, por un lado, que no existe ninguna "lengua pura" ya que todas las lenguas provienen de mezclas, y se niega, por otro lado, la existencia de "lenguas híbridas" ya que se dice que no son "lenguas" sino realizaciones plurilingües, es decir que los hablantes que producen discursos híbridos lo hacen empleando elementos, no de una, sino de diferentes lenguas.

En cuanto a la cuestión de si existen o no "lenguas puras", hay que distinguir, en primer lugar, entre aquellas afirmaciones que se refieren a un estado actual concreto de una lengua y aquellas que argumentan con su pasado. El problema más banal de los dos es el segundo, ya que no cabe duda de que todas las lenguas son "híbridas" en su composición histórica: el inglés es una lengua germánica altamente romanizada, el español una lengua de fuerte influencia vasca, griega, latina, francesa, italiana, inglesa, náhuatl etc. Pero la hibridez en algún momento de la historia puede desembocar en la total integración de los elementos, es 
decir, en la homogeneización del sistema lingüístico. En un sentido puramente histórico, una palabra como "chocolate", por ejemplo, da muestra del carácter "híbrido" del léxico español, pero evidentemente no supone ninguna mezcla ni plurilingüismo en la actualidad ${ }^{4}$.

Algo más compleja es la cuestión de si existen lenguas "puras" en un estado actual concreto. Recordemos que Saussure, al discutir este problema, proponía buscar las formas linguiísticas "puras", si hacía falta, en los dialectos o sub-dialectos más apartados si en las lenguas "grandes" no se encontraba pureza suficiente ${ }^{5}$. Pero hay razones para preguntarse si lo que proponía Saussure no se refería, en realidad, a un mito. Ya los famosos estudios de Gauchat (1905) habían desmontado el mito del habla local completamente unitaria, y sabemos que hasta en las zonas dialectales más apartadas suele haber un cierto grado de variación, incluso a nivel individual.

Pero tanto Saussure como Gauchat carecían de una teoría de la variación lingüística coherente que les permitiese describir adecuadamente la relación entre una posible concepción de un sistema lingüístico social y la variación individual, sin que la variación individual sea solo parole derivable del sistema ${ }^{6}$. La noción de sistema como sistema funcional "puro" fue tantas veces criticada, entre otras cosas porque era evidente que la realidad lingüística no seguía un modelo en el que los discursos actuales correspondían a un solo sistema y que este se veía reflejado inmediatamente en ellos. La primera crítica se refiere al "monolingüismo" de los hablantes y a la existencia de variedades: cada hablante es "plurilingüe" o, por lo menos, "plurivarietal" en la medida en que domina más de una lengua funcional, más de un dialecto, sociolecto o estilo. Pero también sería falso pensar en la separación perfecta de estas unidades como unidades discretas en el habla del individuo. El individuo "plurivarietal" no habla necesariamente una variedad en cada momento determinado, no habla, por ejemplo, un dialecto sevillano "puro" en casa y español estándar en el trabajo: puede realizar elementos de distintas variedades en un mismo discurso, o bien de forma "horizontal" o "sintagmática", cambiando de variedad en una especie de alternancia de códigos, o bien de forma "vertical" o

\footnotetext{
${ }^{4}$ Este ejemplo, que parece exagerado, nos ha servido para criticar la diferenciación tradicional establecida por Weinreich (1953/1968) y repetida en muchos trabajos, entre "interferencias en el habla" e "interferencias en la lengua": para Weinreich, la interferencia en el habla es aquella que se debe al contacto actual, la interferencia en la lengua, en cambio, es el resultado del contacto adoptado en la lengua. En este sentido, "chocolate" sería hoy una interferencia del náhuatl en la lengua española - con lo cual, en nuestra opinión, el término interferencia quedaría inutilizable. Cf. (también sobre el problema de la distinción entre "interferencia involuntaria" y "préstamo"), Kabatek 2000, p. 27-41.

${ }^{5}$ Cf. Saussure 1916:128 : «L'étude synchronique n'a pas pour objet tout ce qui est simultané, mais seulement l'ensemble des faits correspondant à chaque langue; dans la mesure où cela sera nécessaire, la séparation ira jusqu'aux dialectes et aux sous-dialectes. »

${ }^{6}$ Estas y las siguientes líneas tienen su fundamento en la teoría variacional de Eugenio Coseriu y están estrechamente relacionadas con discusiones con Coseriu; un ejemplo de ello es el capítulo "Das Korrekte und das Exemplarische" (Lo correcto y lo ejemplar) en Kabatek/Murguía 1997, 207-219.
} 
"paradigmática", con la presencia de "interferencias" de una variedad en otra. A esto se refiere la segunda crítica de una descripción monolítica del sistema: hay que separar la abstracción que es el sistema lingüístico del discurso actual, y en el discurso actual no hay sólo variación individual dentro del marco de un sistema estable, sino que puede haber perfectamente elementos pertenecientes a más de un sistema. La competencia lingüística no se limita a la atribución de un elemento determinado a un sistema sino que comprende la capacidad de atribuir los discursos actuales a varios sistemas, varias "lenguas" o varias variedades. Los discursos actuales pueden comprender tanto elementos de distintas lenguas históricas como elementos de variedades de una misma lengua, y en este sentido son discursos "híbridos". Estos discursos "híbridos", también pueden limitarse a la variación entre subvariedades de un mismo dialecto, sin que su "hibridez" llame para nada la atención de los hablantes. Las subvariedades tienen, sin embargo, existencia real, y no solo para los lingüistas. Aunque un mismo hablante realice en sus discursos varios subsistemas, estos siguen funcionando como sistemas y son identificados como tales por los oyentes a la hora de comprender los discursos, o sea, a la hora de atribuirlos a sistemas.

El hablante sevillano, por ejemplo, seseante en casa y distinguidor en el trabajo con compañeros no andaluces, puede cambiar de una variedad a otra en un mismo discurso o presentar rasgos de una variedad hablando la otra ya que él como individuo se caracteriza precisamente por emplear las dos. Y el oyente será capaz de atribuir cada elemento del discurso concreto a los diferentes sistemas en cuestión ${ }^{7}$.

Los discursos pueden, pues, ser monosistemáticos o plurisistemáticos. Pero los sistemas en sí siempre son monosistemáticos, lo cual es casi una tautología ya que lo que funciona debe funcionar, y un sistema solo tiene existencia si es funcional. Esto no excluye que la pluralidad de los sistemas, a su vez, pueda formar, en un nivel superior, un "sistema de sistemas", el que tradicionalmente se llama diasistema ${ }^{8}$.

En los paisajes europeos tradicionales, la situación más frecuente solía ser la de hablantes que presentaban una variación mínima entre variedades muy afines, es decir, hablantes que hablaban su dialecto local y alguna variedad semejante, siendo el uso de lenguas muy distantes más bien la "excepción” de algunas zonas (como de las zonas vascófonas en contacto con lenguas románicas). Esto no corresponde, sin embargo, a ninguna

\footnotetext{
${ }^{7}$ Una muestra de esa capacidad creativa de atribución es la creatividad al comprender a los extranjeros en la que el oyente tiene que "crear" un sistema antes no conocido. Es frecuente en hablantes de lengua materna alemana, por ejemplo, la confusión de las vibrantes españolas, con el resultado de que a veces pronuncian vibrantes múltiples, "erres dobles" en palabras como caro, pero etc. Los oyentes suelen darse cuenta del "sistema" diferente, atribuyendo los elementos a un sistema coherente.

${ }^{8}$ El término, frecuentemente mal atribuido, es de Weinreich 1954.
} 
"universalidad": en muchos lugares del mundo, la coexistencia de lenguas o de variedades más distantes es lo "normal", e incluso pueden convivir en espacios apartados y comunidades relativamente pequeñas lenguas a veces tipológicamente diversas, con larga tradición de coexistencia.

Las lenguas son, pues "puras" como sistemas, pero los discursos pueden (y suelen) ser "impuros" cuando en ellos se realiza más de un sistema. Se podría objetar que la postulada "pureza" del sistema solo puede ser una abstracción, una proyección que no deja lugar a que este cambie. Pero precisamente porque es una abstracción hecha a partir de los discursos concretos, los sistemas son dinámicos ya que se proyectan nuevamente en cada momento del hablar concreto; su dinamismo no es un dinamismo inherente del sistema mismo sino de los discursos que lo generan.

La segunda cuestión, la de la existencia de "lenguas" híbridas, queda contestada ya en el punto anterior: las "lenguas híbridas" no existen si por lenguas entendemos sistemas lingüísticos. Se podría hablar de lenguas híbridas si por ello entendiéramos la práctica discursiva de emplear elementos de dos o más lenguas. Pero a esta práctica preferimos llamarle "discursos híbridos", o aún mejor, "discursos plurisistemáticos”, para evitar connotaciones no deseadas. En cierto sentido, se podría hablar de "lenguas híbridas" al hablar de la composición etimológica de una lengua, aunque en este sentido no hay lengua que no sea híbrida, pero existen lenguas en las que el origen plural es más reciente o destaca más que en otras, como es el caso del mencionado inglés, germánico-románico, o del urdu y del hindi, lenguas de pasado en parte común pero de mezclas distintas que llevaron a su diferenciación.

Para esquematizar lo dicho, podemos distinguir discursos (o "textos") plurisistemáticos (1 b) de discursos (o “textos") monosistemáticos (1 a):

esquema 1: discursos monosistemáticos y discursos plurisistemáticos

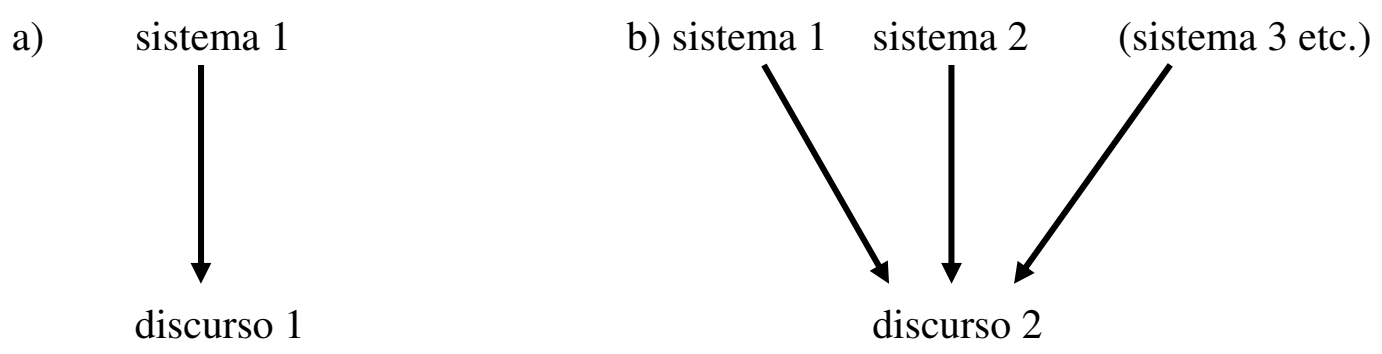

El discurso 1 es un discurso "monolingüe" o "monovarietal" mientras que el discurso 2 es plurilingüe o pluridialectal. En una perspectiva diacrónica, es posible - aunque no necesario - 
que la "mezcla" en b) desemboque en la fusión de ambos sistemas en uno y en la construcción de un nuevo sistema unitario, como en el esquema 2:

esquema 2: "homogeneización" diacrónica

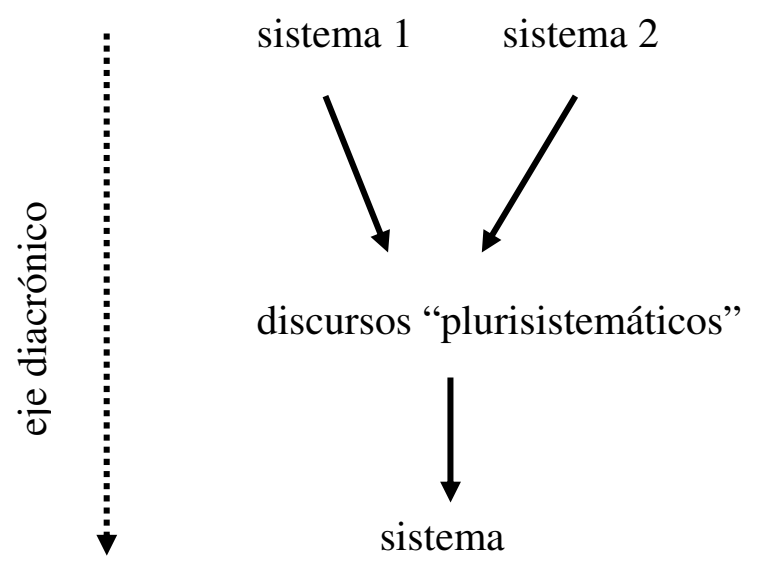

Este proceso se podría describir más detalladamente ya que los factores que intervienen en él son sistematizables por lo menos en parte: grado de presencia de elementos de los distintos sistemas en los discursos, relación L1-L2 de los sistemas en contacto para los hablantes que producen los discursos, prestigio de las variedades, etc.

Hasta aquí podemos afirmar que el debate entre "hibridez" y "pureza" no puede ser, en realidad, un debate teórico a no ser que se confundan los conceptos: existen sistemas lingüísticos, históricamente compuestos por elementos procedentes de diferentes lenguas, que permiten la producción de discursos monovarietales o plurivarietales. Mirando más de cerca las discusiones, no parecen referirse realmente al estatus teórico de estas entidades y ni siquiera se plantean normalmente aclararlo. Se trata, en la práctica, más bien de discusiones acerca de fenómenos empíricos concretos.

\section{La perspectiva de los hablantes}

La objeción entre una perspectiva lingüística y una perspectiva de los hablantes necesita comentarse para que no se malinterprete. Se trata de la distinción - idealizada, por supuesto entre el objeto de la lingüística, que es el lenguaje tal y como es, un objeto intersubjetivamente comprobable y al que se llega mediante la aplicación de métodos basados en fundamentos teóricos, y el objeto de la perspectiva subjetiva que con pleno derecho se 
limita a una visión parcial de las cosas. Con esto no pretendemos negar ni la subjetividad de los lingüistas ni la posibilidad del afán objetivo por parte de los hablantes; queremos, sin embargo, señalar dos finalidades distintas, una objetiva y otra subjetiva.

Lo propio de la visión subjetiva es la percepción de los objetos desde un ángulo determinado y $\sin$ necesidad de abandonar ese ángulo. En cuanto a la lengua y las variedades, la subjetividad implica un yo situado, y una situación con respecto a una lengua o a diferentes lenguas que se expresa en una relación de posesión: yo hablo mi lengua. La posesión no es un hecho estático sino un proceso dinámico de apropiación que suele estabilizarse ya en la infancia, pero también puede llegar a modificarse a lo largo de la vida. Mientras la visión objetiva busca una situación por encima de los objetos sin apropiación de ninguna de las lenguas, la visión subjetiva ve las lenguas desde un punto de vista particular, distinguiendo lo propio de lo ajeno y percibiendo grados de distancia entre la propia lengua y la de los demás. Pero si aplicamos la distinción establecida en 2 entre lengua y discurso, no deberíamos ahora caer en el error de identificar la "situación" social, ese posicionamiento lingüístico que acabamos de mencionar, con una lengua monosistemática entendida en el sentido esbozado. Esta identificación es muy frecuente y lleva precisamente a algunos de los malentendidos más graves en el contexto del tema que estamos tratando. El hablante puede producir discursos que corresponden a un solo sistema lingüístico, como en el esquema 1 a), o bien discursos de diferentes sistemas, como en 1 b). Lo que es importante es que la apropiación, la construcción de una identidad social, funciona no con respecto al grado de "pureza" de estos discursos sino con respecto a la connotación asociada con ellos, que es independiente de su grado de pureza. Si un hablante realiza discursos que corresponden a un único sistema como en 1 a), se identificará con ellos igual que un hablante que realiza discursos como en 1 b). Y es más: la producción de los discursos puede ser altamente dinámica en un mismo hablante, y puede ser que un mismo hablante realice unas veces discursos como los de 1 a) y otras discursos como en 1 b). Esto, sin embargo, no significa que se sienta más "puro" cuando habla como en 1 a) ni más "híbrido" cuando habla como en 1 b). Para algunos hablantes, la identidad está más asociada a discursos "puros" y para otros a discursos "híbridos". Para dar un ejemplo: un hablante gallego de las zonas dialectales occidentales que habla unas veces con seseo sistemático como en los dialectos tradicionales de su zona y otras veces con un sistema distinguidor en el que solo esporádicamente aparecen muestras de seseo, es decir que habla "con seseo puro" en algunas circunstancias y con una mezcla híbrida entre dos sistemas en 
otras, ambas formas de hablar pueden corresponder a su "identidad", o a facetas distintas de la misma, sin necesidad de priorizar una u otra 9 .

Si los "discursos híbridos" no son ni mejores ni peores que los discursos "puros" ya que ambos tipos de discurso "funcionan" (aunque funcionen de manera objetivamente diferente), ¿por qué encontramos tanto críticas como defensas entusiastas de ambos?

Para encontrar una respuesta a esta pregunta, necesitamos antes aclarar una confusión en la argumentación que es muy típica en el discurso político e ideológico y que a veces no es solo confusión, sino estrategia consciente del debate político. Se trata de una confusión temporal entre lo pasado, lo presente y lo futuro, y se puede ilustrar con referencia al esquema 2: hemos visto que los sistemas lingüísticos siempre son "híbridos" etimológicamente, es decir que derivan de diferentes momentos de mezcla. De esto se puede derivar que los actuales discursos de mezcla pueden, a lo largo del tiempo, llegar a sentar la base de una confluencia, pueden, en un proceso de "homogeneización”, producir nuevas "lenguas puras".

Pero un futuro posible no es lo mismo que un futuro cierto o que el presente, y una simple posibilidad de evolución no garantiza de ningún modo que llegará a producirse. Si algunos de los defensores del spanglish, del fenómeno discursivo de la mezcla híbrida de elementos españoles e ingleses ${ }^{10}$, ven en esta mezcla una futura lengua, lo que indican es una posibilidad, pero no una evolución garantizada ${ }^{11}$. Al mismo tiempo, no se puede negar esa posibilidad como mera posibilidad. Se puede señalar únicamente que se trata de una mera cuestión de especulación y que los indicios de probabilidad de que se convierta en realidad son, más bien, pocos ${ }^{12}$.

\footnotetext{
${ }^{9}$ Hay que señalar, sin embargo, que objetivamente los discursos híbridos llevan en sí referencias a distintos sistemas y, por lo tanto, indican un cierto dinamismo social mientras que los discursos monosistemáticos indican mayor estabilidad social.

${ }^{10}$ Manuel Alvar ya señaló, a respecto de la mezcla entre español e inglés, que habría que tratar por separado las diferentes situaciones: "estar sobre la tierra durante siglos nos permite hablar del español de, mientras que establecimientos transitorios, válidos para los estudios de sociolingüística, valdrán para estudios sobre el español en, que son otra cosa ... Tenemos un español invadido por el inglés en territorios que pertenecieron a la Corona, y tras la independencia a México; tenemos un inglés invadido por el español a causas de ciudadanía, trabajo o exilio político. Son, pues, dos situaciones totalmente distintas y que requieren tratamientos diferentes." (Alvar 1996: 100)

${ }^{11}$ Así, Ilán Stavans, máximo defensor (e inventor) del spanglish, habla del spanglish como si ya fuera una lengua, o por lo menos, como si fuera una lengua in statu nascendi: "A cada rato lloramos la muerte de otra lengua en el Globo. ¿Por qué no celebramos de igual manera el nacimiento de una nueva? Puede que nos disguste el spanglish ... Puede que nos cause risa ... Puede que nos inspire ... Todas ellas son reacciones normales. Pero únicamente estudiándolo podremos entender su función y vitalidad. Yo soy de la opinión de que su gestación es una oportunidad extraordinaria para entender cómo se forman los idiomas en general: sus causas y su posible desarrollo." (Entrevista a Stavans en el diario La Nación, en Fairclough 2003, 188).

${ }^{12}$ No queremos entrar aquí en esta polémica, pero hay que señalar que el nombre de spanglish se aplica a toda una gama de posibles mezclas entre español e inglés: aparece, por un lado, para designar un español hablado con influencia inglesa (particularmente frecuente en inmigrantes de primera generación), pero al mismo tiempo designa también el inglés hablado con influencia del español (frecuente sobre todo en inmigrantes a partir de la segunda generación), y, además, para designar toda una serie de fenómenos escritos, tanto literarios como no literarios. Incluso es usado para referirse al español hablado o escrito en los países hispanófonos que presenta
} 
Con todo, las discusiones acerca de la especulación sobre el posible futuro de los discursos híbridos no son, en el fondo, más que proyecciones anacrónicas de problemas actuales, igual que los argumentos contrarios, los que procuran justificar el purismo argumentando con el pasado $^{13}$. Para analizar las motivaciones del conflicto entre defensores de purismo e hibridez, en vez de mirar hacia el futuro o hacia el pasado, habría que fijarse más bien en constelaciones presentes.

El conflicto deriva precisamente de la mencionada apropiación individual de la lengua, o, mejor dicho, de su carácter particular, social e individual al mismo tiempo. La lengua es un fenómeno social que solo tiene existencia en su interindividualidad pero que únicamente se manifiesta en discursos individuales. Es decir que la lengua como objeto interindividual solo existe si simultáneamente es tanto la lengua de un sujeto como la de otro(s) - es decir, es tanto la lengua del yo como del tú. Pero esta equiparación es paradójica e implica un alto potencial de conflicto. Solo de manera idealizada pero no real, la lengua, la del yo y la del tú son idénticas. En realidad, el yo y el tú no pueden ser totalmente iguales, y están sometidos a dinámicas en parte divergentes, así, la cuestión de la lengua no se resuelve de manera unánime. Los hablantes suelen aceptar como normales ciertos desvíos individuales de lo que ellos consideran "la lengua", pero se sienten amenazados cuando estos desvíos ya no son solo fenómenos individuales sino cuando parecen estar desviando la lengua misma.

Cuando, por ejemplo, ciertos hablantes del catalán empezaron a criticar el catalán hablado o escrito por otros en la polémica de los años noventa entre catalán "heavy" y catalán "light"14, no lo hacían para criticar un determinado comportamiento individual ajeno, sino porque este comportamiento les afectaba directamente ${ }^{15}$ : los hablantes quieren reconocerse ellos mismos en el habla de los demás miembros de su comunidad, y si no se reconocen, se preocupan porque sienten que la comunidad se aleja de ellos o ellos se alejan de la comunidad.

Este problema de identidad individual con respecto a la identidad del grupo es también un problema de categorización: un subgrupo de hablantes se apropia de la categoría "català" que el hablante tradicional asocia, no con las formas "nuevas" que oye o lee sino con su propia forma de hablar. Es decir que la apropiación del nombre de la lengua por parte de hablantes con otras características invade el propio terreno, la propia identidad del hablante, lo cual le

influencias del inglés. Esto quiere decir que en la práctica spanglish es un nombre para designar un continuo de fenómenos que se caracterizan por contener elementos de dos lenguas, la española y la inglesa, y antes de pronosticar que a partir de esta mezcla va a nacer una lengua habría que precisar cuál de los múltiples fenómenos actuales sería su origen.

${ }^{13}$ Cf. Kabatek 2007.

${ }^{14}$ Para esta distinción, véase, entre otros, Pericay / Toutain 1986, Pazos 1990, Tubau 1990, Kailuweit 2002.

${ }^{15}$ Así, en Tubau 1990, 163, leemos el siguiente comentario a este problema: “A mi em preocupava molt [...] que eres català, llegies el diari i no t'hi reconeixies." (subrayado nuestro) 
incita a reaccionar, y defender lo suyo propio ${ }^{16}$. Este mecanismo explica numerosos fenómenos de crítica del lenguaje. Las críticas surgen porque los individuos, desde su punto de vista "subjetivo", conciben la lengua, lo que ellos categorizan con un nombre que sienten ligado a su identidad, como algo estable e inalterable (o por lo menos no alterable sin su acuerdo), algo suyo, algo que tienen que defender para no perderlo.

La identificación entre "mi lengua" y "la lengua" se da por la categorización idéntica; ambas son para el hablante la misma cosa ${ }^{17}$. La discusión entre "puristas" y "antipuristas" suele ser, pues, una discusión sobre el derecho de apropiación de la lengua por un grupo determinado de hablantes, y los argumentos, se refieran ellos al pasado o al futuro, no son más que intentos de dar apoyo o autoridad a una postura determinada.

Hasta aquí hemos hablado de "purismo" e "hibridez" con referencia a dos tipos de situaciones diferentes: por un lado, por ejemplo a las variedades híbridas que se producen en situaciones de contacto entre gallego y castellano o las variedades catalanas influenciadas por el español, y por otro, a la mezcla entre español e inglés llamada spanglish. La diferencia fundamental entre los dos tipos es que en el primer caso, dentro de una comunidad se forman grupos cuyas características lingüísticas muestran influencias de otra lengua pero que siguen formando parte de la misma comunidad, y en el segundo caso, parece que se está formando una comunidad nueva, un espacio híbrido ${ }^{18}$ con posibilidad de emancipación, de independización con respecto a las lenguas en contacto. Si el mecanismo que nutre las discusiones en el primer caso es el descrito en el párrafo anterior, habrá que preguntarse por qué en el segundo caso también hay discusión ya que, por lo que parece, el mecanismo de la identificación con la misma categoría no puede funcionar allí donde se trata aparentemente de otra comunidad con una categoría distinta.

El primer tipo se refiere a discusiones en situaciones dinámicas donde los que discuten quieren intervenir en el dinamismo; quieren, en el fondo, contribuir a que se mantenga la existencia misma del grupo, y no de cualquier manera, sino de la que mejor les guste o convenga. En el segundo caso, sin embargo, parece que la discusión metalingüística ya no tiene sentido porque ya se ha formado otro grupo, con independencia lingüística. De hecho, esto es cierto cuando el "espacio híbrido" realmente se ha independizado y los discursos

\footnotetext{
${ }^{16}$ En realidad, hay que distinguir entre reacciones extropunitivas, como la defensa, e intropunitivas, como la negación de la propia identidad, el menosprecio de la misma y la mayor estima de la identidad ajena; cf. Kabatek 1994.

${ }^{17}$ Con todo, hay que decir que, por razones históricas, la flexibilidad de la categorización puede ser muy amplia en ciertas comunidades; así, puede haber también una conciencia taxonómica de pertenencia de una variedad a una entidad superior; así, un andaluz ve como totalmente compatible - salvo en intentos recientes de ruptura llamar a su propia habla tanto andaluz como español. (cf. Narbona Jiménez 2003).

${ }^{18}$ Cf. Bhaba 1994, 11.
} 
híbridos ya no dependen de las lenguas de las que originalmente derivan, es decir, cuando a raíz de lo híbrido ha nacido una lengua. Entonces sería absurdo criticar la hibridez. A nadie se le ocurriría en la actualidad criticar la romanización medieval del inglés o la arabización del español; esta crítica tendría a lo mejor sentido en la época de Guillermo el Conquistador, en el caso del inglés, y de Al-Andalus en el caso del español, pero hoy en día sería un anacronismo. Pero a diferencia del inglés o del español, el spanglish, aunque el nombre parezca insinuarlo ${ }^{19}$, no es, como ya hemos dicho, una lengua de composición híbrida sino un nombre

${ }^{19}$ Los nombres de las lenguas o variedades, los glotónimos, no implican de por sí ningún objeto homogéneo ni estable, y aún menos un objeto inalterable. Los hablantes necesitan para su propia construcción identitaria verse reflejados en comportamientos lingüísticos que consideran suyos. Y el acceso a estos objetos, la conciencia de ellos, les es dada mediante la posibilidad de nombrarlos. Nombrando los objetos los identifican como tales y los distinguen de otros. Pero de ningún modo se puede derivar una determinada particularidad del objeto por el mero hecho de poder nombrarlo, siendo la única particularidad que el acto de nombrar exige la percepción o el conocimiento de alguna diferencia del objeto nombrado con respecto a otros. Esto vale del mismo modo para los objetos lingǘsticos, que en el fondo no son de naturaleza distinta que otros objetos y cuya diferencia fundamental con respecto a los llamados objetos "primarios" (los pertenecientes a la mal llamada "Objektsprache", al lenguaje referido a los objetos, término no muy afortunado ya que implica que el metalenguaje como opuesto al lenguaje de los objetos no se refiere a objetos) consiste en la coincidencia entre el medio que nombra y el objeto que es nombrado. Los glotónimos se refieren a entidades lingüísticas y las identifican, pero no implican de por sí ni juicios acerca de la homogeneidad o heterogeneidad o a la estabilidad interna del objeto ni del grado de diferencia con respecto a otros objetos y de alguna manera ni siquiera del grado de existencia real del objeto como objeto social.

En cuanto a la homogeneidad o la heterogeneidad del objeto, los glotónimos pueden denominar, al igual que los nombres comunes de uso no metalingüístico, por lo menos tres tipos de objetos, por un lado, objetos estructuralmente heterogéneos que no necesariamente confluyen en los mismos enunciados pero que se identifican como objetos semejantes e históricamente relacionados, las "lenguas históricas" como la lengua española, la lengua inglesa o la lengua francesa como conjuntos de variedades lingüísticas con un denominador común. El denominador común incluye aquí tanto la variedad o las variedades estándar como toda una serie de variedades diferenciadas. El segundo caso es el de los objetos heterogéneos que confluyen en el mismo enunciado. Cuando la confluencia es habitual y convive con la existencia de los objetos por separado, esta confluencia se puede reconocer como mezcla o hibridez. El denominador, como p. ej. en el caso de spanglish, de portunhol o de castrapo, subsuma aquí una práctica de hablar que combina elementos de distintas lenguas. Por último, los glotónimos pueden denominar objetos estructuralmente homogéneos (o langues en el sentido saussureano), que no son dados como entidades concretas ya que son abstracciones hechas a partir de los enunciados concretos.

Tampoco implican los glotónimos que tenga que existir una diferencia real y objetiva de una cierta importancia con respecto a otro objeto. Debe existir, eso sí, una diferencia mínima con respecto a otro objeto para poder nombrarlo, si no se trataría de un caso de sinonimia. Así, desde un punto de vista de las meras posibilidades de nombrar, no hay razones objetivas para no llamar valenciano al valenciano, mallorquín al mallorquín y hasta argentino al español hablado en Argentina, aunque, como veremos, hay también razones subjetivas fundadas de no hacerlo (o por lo menos de no hacerlo con un sentido que vaya más allá de la descripción de diferencias frente a otros objetos). Ni siquiera implican los glotónimos que el objeto denominado sea realmente un objeto social, ya que existe también la posibilidad de denominar el habla de un individuo mediante un glotónimo, aunque tal vez en un sentido más bien figurado, ya que el habla de un individuo no es una lengua propiamente dicha. Cuando hablamos de la lengua de Cervantes, por ejemplo, hoy en día nos solemos referir por metonimia a la lengua española, pero la lengua de Cervantes también puede ser la lengua del autor concreto Miguel de Cervantes, y en principio no hay razones para no denominarla cervantino. Las lenguas individuales pueden también ser artefactos propuestos por un individuo, como el newspeech de Orwell o el spanglish de Ilán Stavans, que se apropia de un glotónimo para sus usos individuales. Mis hijos llamaban "susánico" al habla particular de su hermana pequeña que estaba aprendiendo a hablar, y para ellos esta 'variedad' implicaba reducciones de complejidades silábicas tanto como simplificaciones gramaticales y léxicales que ellos, los mayores, lograban imitar con una cierta gracia.

Todo lo dicho en esta nota se refiere a unos principios fundamentales del nombrar y no se debe ni confundir con la práctica de nombrar esta o aquella entidad en esta o aquella sociedad ni tampoco con ciertas connotaciones, resultantes de esas prácticas y asociadas con los nombres de las lenguas. Así, por ejemplo, decir que el 
que se da a una serie de discursos que contienen elementos de dos lenguas; pero el spanglish no se ha independizado de estas lenguas ni se ha emancipado frente a ellas, aunque haya, por ejemplo, poetas, como Guillermo Gómez-Peña, Tato Laviera u otros performance-artists que expresen su identidad del "espacio híbrido" cultivando el spanglish en su producción poética. Pero este spanglish poético no es lo mismo que la mezcla de inmigrantes cuyo dominio restringido del inglés les lleva a mezclarlo con elementos del español; el spanglish poético suele ser expresión de aquellos que se mueven con soltura en los dos idiomas de contacto, y del éxito literario de los poetas no se podrá derivar el éxito social de los inmigrantes. Si los hablantes híbridos se identifican, no sin razón, con las producciones poéticas híbridas, esto no debería servirles de engaño en una sociedad en la que el prestigio está del lado del inglés. Evidentemente no hay razón para criticar, desde una postura purista exagerada, el spanglish de la producción literaria; como mucho, se puede criticar el producto individual desde una crítica estética. Pero se critica con razón el que a los hablantes que mezclan por no dominar o no saber separar las lenguas se les diga que sigan hablando así ya que están en un espacio híbrido que merece todo el respeto de los demás. Puede ser que lo merezca, pero es fácil predicarlo desde la posición del que tiene acceso al mundo prestigioso del inglés "puro". El "tercer espacio" existe, pero debería existir, por lo menos hasta que no se haya consolidado, como opción de los hablantes, no como necesidad o prisión de la que no se puede salir aunque se quiera.

\section{Demagogia y solidaridad}

Con este último aspecto, después de haber hablado de la perspectiva linguiística "objetiva" y la perspectiva subjetiva de los hablantes, cabe ahora introducir una tercera, la de los que opinan sobre las cuestiones de purismo e hibridez sin formar parte ellos mismos de los grupos afectados. Esta perspectiva puede tener distintas facetas, desde la persona ajena que se

\footnotetext{
valenciano puede ser nombrado y que ese nombrar puede referirse a una realidad diferenciada del catalán únicamente es decir algo acerca de las posibilidades del nombrar; y decir que el valenciano, aunque se distinga, es parte del catalán como lengua histórica o no, indica otras posibilidades del nombrar, pero indica, al mismo tiempo, que hay una decisión acerca de la relación jerárquica entre dos entidades, y esa decisión no está en el nivel de los nombres mismos sino en el nivel de la articulación de la voluntad de los valencianos de considerarse o no parte del conjunto de los que hablan la lengua catalana, para lo cual hay argumentos en favor y en contra y al final es una decisión, en último término, política y no lingüística. Por lo tanto, el lingüista no puede decidir por el mero análisis de los nombres el papel social que debe ocupar una entidad designada, solo puede aducir, eso sí, argumentos históricos que fundamenten una u otra postura sin que por ello pueda ofrecer una "decisión" objetiva: las decisiones, sobre todo si se trata de decisiones sobre algo futuro, pertenecen al mundo de lo posible y no de lo real y objetivamente dado. Tampoco el mero hecho de llamar algo que se quiere distinguir spanglish le da a lo distinguido un nivel superior que si lo llamáramos "mezcla híbrida entre español e inglés". El spanglish, por el mero hecho de ser nombrado, no está en el mismo nivel que el español o el inglés, por ejemplo, ni es inferior o superior, es simplemente otra cosa.
} 
solidariza con otros hablantes hasta los que procuran aprovecharse del potencial de ciertos grupos para ganar la simpatía de sus miembros o para conseguir poder para la realización de sus propios fines. En este caso, podemos calificar la actitud de estos líderes de demagógica, en el sentido original del que alaba ciertas propiedades de un grupo para ganar su simpatía.

El demagogo es el que, sin pertenecer a los grupos realmente implicados, llama la atención sobre ciertas características de estos grupos y les atribuye valores. Como el demagogo viene de fuera del grupo, el grupo suele valorar su juicio como más objetivo y de más valor que un juicio semejante por parte de un miembro del grupo. El demagogo viene de una posición social asegurada y les dice a los que mezclan español e inglés que lo que hacen es expresión de una nueva cultura, que es su identidad, que es el futuro. Les confirma así un comportamiento que él mismo, conocedor perfecto del inglés o del inglés y del español, no tendrá que vivir. Si el spanglish llega a emanciparse o si los hablantes siguen discriminados, él no lo tendrá que vivir. El demagogo (o el solidario, según se mire) también es el romanista alemán que les dice a los hablantes de lenguas minoritarias que las cuiden. El demagogo es el protagonista de políticas lingüísticas que fomentan una educación que él mismo no tendrá que padecer. Y es demagogo tanto el que propone lenguas del imperio para gustar al imperio como el que propaga lenguas minoritarias para gustar a sus hablantes. Y el demagogo - o solidario - no es, de por sí, ni malo ni bueno, es humano simplemente, pero los que pertenecen a los grupos afectados tendrán que ser conscientes si les conviene o no hacerle caso.

\section{La dignidad}

En este breve recorrido a través de diferentes facetas de lo "puro" y lo "mezclado" casi nos olvidamos de uno de los puntos claves de la cuestión inicial: la dignidad de las lenguas. Hay una dignidad general y universal del lenguaje de la que ya nos habla Aristóteles cuando define lo particular del ser humano mediante la capacidad lingüística. El lenguaje existe en forma de sistemas de signos que están por encima de los demás sistemas ya que los signos lingüísticos son los primarios; son ellos los que permiten el acceso a los demás sistemas. La dignidad de la que habla el gallego de la introducción, sin embargo, no puede ser la dignidad general del lenguaje, pues cualquier discurso - mezclado, puro, unilingüe, plurilingüe, vulgar, familiar, académico, etc. - es expresión de esa dignidad universal. El gallego parece hablar de otra cosa, de la invasión de aquel neohablante en un terreno que considera como suyo, que identifica con sus antepasados y que defiende porque le parece digno de conservación. Esta 
dignidad es la dignidad de la lengua, la cual no es otra cosa que la dignidad de sus hablantes, una dignidad que es dada por el carácter histórico mismo de la lengua, esa historicidad que lleva en sí los recuerdos de las generaciones anteriores y de los otros presentes que la comparten. La historicidad no se opone al futuro, es su condición. Pero se opone a la demagogia de los que predican el futuro desde la hibridez actual, sin saber si este futuro jamás se producirá y sin tener que vivirlo ellos mismos.

\section{Bibliografía}

Alvar, Manuel (1996): "Los Estados Unidos", en: Manuel Alvar (ed.): Manual de dialectología hispánica. El español de América, Barcelona: Ariel, 90-100.

Bhaba, Homi K . (1994): The location of culture, London / New York: Routledge.

Castillo Lluch, Mónica / Kabatek, Johannes (eds.) (2006): Las lenguas de España. Política lingüística, sociología del lenguaje e ideología desde la Transición hasta la actualidad, Frankfurt am Main/Madrid: Vervuert/Iberoamericana.

Coseriu, Eugenio (s.a.): El problema de la corrección idiomática, ms. no publicado.

Coseriu, Eugenio (1987): „El gallego y sus problemas. Reflexiones frías sobre un tema candente", in: Lingüística española actual 10 (1987), S. 127-138.

Fairclough, Marta (2003): "El (denominado) Spanglish en Estados Unidos: polémicas y realidades", Revista Internacional de Lingüística Iberoamericana 1, 2, 185-204.

García Canclini, Néstor (1990): Culturas híbridas. Estrategias para entrar y salir de la modernidad, México: Grijalbo.

García González, Constantino (1985): Temas de lingüística galega, A Coruña.

Gauchat, Louis (1905): „L'unité phonétique dans le patois d'une commune“ in: Aus romanischen Sprachen und Literaturen. Festschrift Heinrich Morf, 175-232.

Gugenberger, Eva (2004): „Sprache - Identität - Hybridität: Das Beispiel der Galicier/innen in Galicien und Argentinien“, Grenzgänge 11, 2004, S. 115-149.

Gugenberger, Eva (2008): „El castellano y las lenguas regionales en España: Bilingüismo e hibridación”, in: Doppelbauer, Max / Cichon, Peter: La España multilingüe. Lenguas y políticas lingüísticas de España, Wien: Praesens, p. 31-52.

Hall, Robert A. jr. (1950): Leave your language alone, Ithaca: Linguistica.

Kabatek, Johannes (1991): "Interferencias entre galego e castelán: problemas do galego estándar", in: Cadernos de Lingua 4 (1991), 39-48. 
Kabatek, Johannes (1994): "Auto-odi: Geschichte und Bedeutung eines Begriffs der katalanischen Soziolinguistik", in: Gabriele Berkenbusch/Christine Bierbach (eds.): Zur katalanischen Sprache: historische, soziolinguistische und pragmatische Aspekte, Frankfurt: DEE, 159-173.

Kabatek, Johannes (1997a): "Dime cómo hablas y te diré quién eres. Mezcla de lenguas y posicionamiento social”, Revista de Antropología Social [Madrid] No 6, 215-236.

Kabatek, Johannes (1997b): "Strengthening identity: differentiation and change in contemporary Galician”, in: Jenny Cheshire/Dieter Stein (eds.): Taming the Vernacular. From Dialect to Written Standard Language, London - New York: Longman, 185-199.

Kabatek, Johannes (2000): Os falantes como lingüistas. Tradición, innovación e interferencias no galego actual, Vigo: Xerais.

Kabatek, Johannes (2003a): "Las categorizaciones de las lenguas, del lenguaje y de los discursos - teoría y ejemplos iberorrománicos”, in: Fernando Sánchez Miret (ed.): Actas del XXIII Congreso Internacional de Lingüística y Filología Románicas. Salamanca 2001, III, 253-262 Tübingen: Niemeyer.

Kabatek, Johannes (2006): "Requisitos para ser lengua: el caso del asturiano y de otras modalidades lingüísticas de España”, in: Johannes Kabatek / Mónica Castillo Lluch (Hrsg.): Las lenguas de España. Política lingüística, sociología del lenguaje e ideología desde la Transición hasta la actualidad, Frankfurt am Main/Madrid: Vervuert, 2006, 141-158.

Kabatek, Johannes (2007): "Dos Españas, dos normalidades: visiones bipolares sobre la situación lingüística en la España actual”, in: Gero Arnscheidt / Pere Joan i Tous (Hrsg.): “Una de las dos Españas...” Representaciones de un conflicto identitario en la historia y en las literaturas hispánicas (Homenaje a Manfred Tietz), Frankfurt am Main / Madrid: Vervuert / Iberoamericana 2007, 803-816.

Kabatek, Johannes /Murguía, Adolfo (1997): „Die Sachen sagen, wie sie sind... “. Eugenio Coseriu im Gespräch, Tübingen: Narr.

Kabatek, Johannes / Ildiko Szijj (en prensa): "Gallego: Historia interna", in: Gerhard Ernst/Martin-Dietrich Glessgen/Christian Schmitt/Wolfgang Schweickard (eds.): Histoire linguistique de la Romania. Manuel international d'histoire linguistique de la Romania, Vol. II, Berlin-New York: De Gruyter.

Kailuweit, Rolf (2002): “Català heavy - català light: una problemàtica de la «lingüística de profans»", Zeitschrift für Katalanistik 15, 169-182. 
Monteagudo, Henrique u. Antón Santamarina (1993): «Galician and Castilian in contact: historical, social and linguistic aspects», in: Trends in Romance Linguistics and Philology, Vol. 5: Bilingualism and Linguistic Conflict in Romance, hrsg. v. Rebecca Posner und John N. Green, Berlin/New York: Mouton de Gruyter, 117-173.

Narbona Jiménez, Antonio (2003): Sobre la conciencia lingüística de los andaluces. Discurso leído en la Real Academia Sevillana de Buenas Letras, Sevilla: Comares.

Pazos, Maria-Lluïsa (1990), L’amenaça del català light, Barcelona: Tibidabo.

Pericay, Xavier / Toutain, Ferran (1986), Verinosa Llengua, Barcelona: Empúries.

Poplack, Shana (1980): "Sometimes I'll start a sentence in English y termino en español. Towards a typology of Code-Switching”, Linguistics 18, 561-618.

Pountain, Christopher (2003): Exploring the Spanish language, London: Arnold.

Saussure, Ferdinand de (1916/1984): Cours de Linguistique Générale, édition critique préparée par Tullio de Mauro, (primera ed. 1972, sobre la base de la edición princeps de Bally, Sechehaye y Riedlinger de 1916) Paris: Payot.

Sijs, Nicole van der (2004): "The role of purism in language development - historical and political aspects", in: Riagáin, Dónall ó / Stolz, Thomas: Purism. Second helping, Bochum: Brockmeyer, 1-24.

Sinner, Carsten (2007): “Spanish, portunhol \& Co.: Hybrid, Interlekt, Kreol...? Zu einem Problem nicht nur auf terminologischer Ebene”, en: Döring, Martin / Osthus, Dietmar / Polzin-Haumann, Claudia (eds.): Sprachliche Diversität: Praktiken - Repräsentationen - Identitäten, Bonn: Romanistischer Verlag, 1-37.

Tubau, Ivan (1990), El català que ara es parla. Llengua i perodisme a la ràdio i la televisió, Barcelona: Empúries.

Weinreich, Uriel (1954): “Is a Structural Dialectology Possible?”, in: Word 10, 388-400.

Weinreich, Uriel (1953/1968): Lenguas en contacto. Descubrimientos y problemas, traducción de Francisco Rivera (original inglés New York 1953) Caracas: Universidad Central de Venezuela.

Whinnom, Keith (1971): „Linguistic Hybridization and the special case of pidgins and creoles“, in: Dell Hymes (ed.): Pidginization and Creolization of Languages, Cambridge, p. 91-116. 